\begin{tabular}{c} 
International Journal of Engineering \& Technology, 7 (3) (2018) $1745-1750$ \\
International Journal of Engineering \& Technology \\
SPC \\
Website: $\begin{array}{c}\text { ww. sciencepubco.com/index.php/IJET } \\
\text { doi: } 10.14419 / \text { ijet. } 7 \text { 7i.15318 } \\
\text { Research paper }\end{array}$ \\
\hline
\end{tabular}

\title{
Enhancing gain of dual band antenna for Wi-Fi/WiMAX applications using array technique
}

\author{
Hiwa Taha Sediq * \\ Department of Information Technology, Shaqlawa Technical Institute, Erbil Polytechnic University, Erbil, Iraq \\ *Corresponding author E-mail: hiwa_eece@yahoo.com
}

\begin{abstract}
This study describes the design of dual rectangular microstrip patch antenna for Wi-Fi and WiMAX wireless communication applications. In this work, the technique of design array patch antennas was used in order to improve the physical antenna characteristics for Wi-Fi and WiMAX device. As a result, the proposed technique causes to increase the gain and directivity of the antenna. Using this method also leads to enhance measurement bandwidth of antenna and some other antenna parameters as mentioned in this research paper. A dual-band microstrip patch antenna is developed for WiMAX/Wi-Fi wireless applications that operate at a minimum frequency of $2.4 \mathrm{GHz}$ and a maximum frequency band of $3.5 \mathrm{GHz}$ with its dimensions is $\mathrm{L}=88.27 \mathrm{~mm}, \mathrm{~W}=171.4 \mathrm{~mm}$ and $\mathrm{h}=1.67 \mathrm{~mm}$. The achieved parameters of dual patch array antenna for $2.4 \mathrm{GHz}$ and $3.5 \mathrm{GHz}$ are (gain of $8.25 \mathrm{~dB}$, directivity of $10.4 \mathrm{dBi}$, measurement bandwidth of $65.82 \mathrm{MHz}$ and measurement return loss of $-20.86 \mathrm{~dB}$ ) and (gain of $7.56 \mathrm{~dB}$, directivity of $8.76 \mathrm{dBi}$, measurement bandwidth of $98.96 \mathrm{MHz}$ and measurement return loss of $-21.38 \mathrm{~dB}$ ) respectively.
\end{abstract}

Keywords: Dual Patch Array Antenna, Gain; WIMAX; Reflection Coefficient; Inset Feed Technique; Radiation Pattern.

\section{Introduction}

The fast development of wireless communication field has grown the demand for antenna technologies with multi-band operating frequencies. Microstrip patch antennas are widely used to design antenna in wireless communication systems because of having a low profile and lightweight [1]. Nowadays this technology becomes very popular due to ease of compatibility and fabrication with Monolithic Microwave Integrated Circuits (MMICs). These antennas are extremely used for wireless communication applications like satellite, radar, and mobile communications because of their planar structure and compactness [2]. In today's advancements, the popularity of the wireless network has been raised to perform the requirements of consumer demand in wireless technology. Despite having some disadvantages such as less gain, low efficiency and narrow bandwidth, these antennas are very popular due to their small size and low weight of microstrip patch antennas. These properties of antennas make the technology most suitable for mobile and wireless devices. In addition, many researchers try to resolve and overcome their problems by making some modifications like using different shapes, array patch methods and slot cut [3]. There is numerous demand for the new type of wireless antennas such as broadband antennas, multi-frequency antennas and small antennas for satellite and mobile communication systems. A dual-band antenna is a kind of antenna, which is designed for two or more different bands to provide various applications like Wireless Communications, Area monitoring, Disaster prevention, Forest fire detection.

Microstrip patch antennas typically consist of a conducting dielectric layer, which is known as the substrate $[4,5]$. This substrate separates the microstrip patch from the ground plane. The patches are generally made of a conducting material such as silver, copper or gold that take some different shape like rectangular, elliptical, circular, square, triangular [6]. Various designed geometrical patches affect the current distribution on the compact antennas. The feed lines and radiating patch are usually printed on the conducting substrate. The range of the rectangular patch length $(\mathrm{L})$ is typically $\left(0.3333 \lambda_{0}<\mathrm{L}<0.5 \lambda_{0}\right)$, where $\lambda_{0}$ is a free space wavelength and the patch thickness antenna (Mt) should be less than $\lambda_{0}\left(\mathrm{Mt}<<\lambda_{0}\right)$. The height $(\mathrm{h})$ of the dielectric conduct substrate has a range between $\left(0.003 \lambda_{0}\right)$ and $\left(0.05 \lambda_{0}\right)$ i.e. $\left(0.003 \lambda_{0} \leq \mathrm{h} \leq 0.05 \lambda_{0}\right)$ and the range of the substrate dielectric constant $\left(\varepsilon_{\mathrm{r}}\right)$ is $\left(2.2 \leq \varepsilon_{\mathrm{r}} \leq 12\right)$ [7]. Moreover, a simple geometrical rectangular patch antenna (RPA) generally operates at a single resonance frequency $\left(\mathrm{F}_{\mathrm{r}}\right)[8]$.

Proper impedance matching of the feed line and the patch is used to control the return loss of antenna and various antenna parameters can be improved by proper feeding location and technique [9]. Various feed techniques are applied for purpose of the perfect matching antenna to feed dual microstrip patch antennas (DMSA) [10], such as inset feed, aperture coupled Feed, coaxial feed, and proximity coupling. In this present investigation, inset feed technique has been used because this technique is one of the common techniques that is typically used for feeding rectangular patch antennas as depicted in Figure 1. The concentration of this investigated paper is the design of dual-band microstrip patch array antenna for Wi-Fi and WiMAX devices in wireless communication. WiMAX is a type of wireless technology standard for (Worldwide Interoperability for Microwave Access) that typically uses for providing wide-area wireless networking. This technology supports both fixed wireless and mobile communications. WiMAX systems are one of the most popular broadband wireless technologies around the world. Its technology is based on the standard IEEE 802.16. Worldwide Interoperability for Microwave Access has the ability to provide wireless internet service for distances longer than standard Wi-Fi to enterprise customers and residential organizations. The Long-Term Evolution WiMAX and $4 \mathrm{G}$ cellular mobile communication standards 
utilizes multiple input multiple outputs to provide a developed data rate of about $1 \mathrm{Gbps}$ [11], [17].

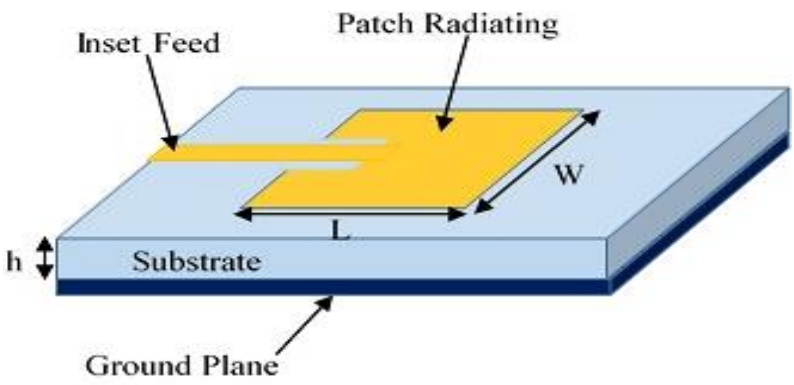

Fig. 1: Simple Rectangular Micro Strip Patch Antenna.

\section{Related work}

Simple inset feed technique has been designed to feed the typical model of microstrip patch array antenna. The number of trial methods has been executed in order to obtain a good impedance matching [12]. Some of the various software can be used to simulate and design the antennas such as ADS, MATLAB, IE3D, SONET-LITE, ANSOFT-Designer, CST Microwave Studio, and HFSS [13]. There are different shapes of the patch antenna such as bow tie, diamond, spherical, elliptical, rhombus, square plate, biconical, etc. [7]. In this work was focused on the design of dual-band microstrip patch array antenna for WiMAX and Wi-Fi devices by using CST Microwave Studio software.

\section{Design procedure}

\subsection{Design of single rectangular patch antenna}

Choice of the dielectric substrate is very important for designing of a microstrip patch antenna. A good proposed antenna cannot be properly designed without proper selection of conducting substrate's parameter such as dielectric constant, height, length, and width. Depending on the performance and requirement different material used as a substrate like Taconic-FR4, PTFE, RT duroid 5880 are some of the commonly used material. In this research paper, the material Taconic-RF-43 dielectric substrate has been selected for the design of the antenna with substrate's thickness (h) of $1.6 \mathrm{~mm}$, dielectric constant $(\varepsilon r)$ of 4.3 and loss tangent of 0.0033 . The resonance frequency (fr) of $2.4 \mathrm{GHz}$ is used for the design of the rectangular microstrip patch antennas. The physical dimensions and the size of the antenna are determined by the following Eqs. (14) [14] as shown in Figure (2a \& 2b). The length (L) and width (W) of patch antennas are $29.05 \mathrm{~mm}$ and $40.7 \mathrm{~mm}$ respectively and the ground plane dimension of $((\mathrm{Lg}=2 \times \mathrm{LL} \mathrm{mm}) \mathrm{X}(\mathrm{Wg}=2 \times \mathrm{W} \mathrm{mm}))$ is considered for the design.

In this study, inset feed technique has been used for the proper feeding of the proposed antenna where the input impedance is $50 \mathrm{ohms}$. In order to archive a correct impedance matching and obtain perfect practical results of antenna parameters, the antenna feeding location should be designed more carefully [15]. The inset-fed length ( $\mathrm{Fi}$ $=9.07 \mathrm{~mm})$ of the patch was calculated using equation (5) and there is a gap $(\mathrm{g})$ of $1 \mathrm{~mm}$ between the inset-fed and the patch. The insetfed width $(\mathrm{Wf}=3.137 \mathrm{~mm}$ ) was obtained by using the calculation tool of the CST Microwave Studio.

Width of the radiating patch (W)

$\mathrm{W}=\mathrm{c} /\left(2 \mathrm{f} \_\mathrm{r} \sqrt{ }\left(\left(\left(\varepsilon \_\mathrm{r}+1\right)\right) / 2\right)\right)$

Effective dielectric constant of the substrate $\llbracket\left(\varepsilon \rrbracket_{-}(\mathrm{eff})\right)$

$$
\llbracket \varepsilon \rrbracket_{-}(\mathrm{eff})=\left(\varepsilon_{-} \mathrm{r}+1\right) / 2+\left(\varepsilon_{-} \mathrm{r}-1\right) / 2[1+12 \mathrm{~h} / \mathrm{w}]^{\wedge}(-1 / 2)
$$

Length extension for patch $(\Delta \mathrm{L})$

$\Delta \mathrm{L}=0.412 \mathrm{~h}\left(\varepsilon_{-}\right.$eff +0.3$)(\mathrm{w} / \mathrm{h}+0.264) /\left(\varepsilon_{-}\right.$eff- 0.258$)(\mathrm{w} / \mathrm{h}+0.8)$

Length of the radiating patch $(\mathrm{L})$

$\mathrm{L}=\mathrm{c} /\left(2 \mathrm{f} \_\mathrm{r} \sqrt{ }\left(\llbracket \varepsilon \varepsilon_{-}(\mathrm{eff})\right)\right)-2 \Delta \mathrm{L}$

Length of the inset-fed (Fi)

$\mathrm{Fi}=\llbracket 10 \rrbracket \wedge(-4)\left(0.001699 \times \llbracket \varepsilon \_r \rrbracket \wedge 7+0.13761 \times \llbracket \rrbracket \varepsilon \rrbracket \_r \rrbracket\right.$ $\wedge 6-6.1783 \times \llbracket \varepsilon_{-} \mathrm{r} \rrbracket \wedge 5+93.187 \times \llbracket \llbracket \varepsilon \rrbracket \_r \rrbracket \wedge 4-682.69 \times \llbracket \varepsilon_{-} \mathrm{r} \rrbracket$

$\wedge 3+2561.9 \times \llbracket \llbracket \varepsilon \rrbracket \quad r \rrbracket \wedge 2-4043 \times \varepsilon \quad \mathrm{r}+6697) \times \mathrm{L} / 2$

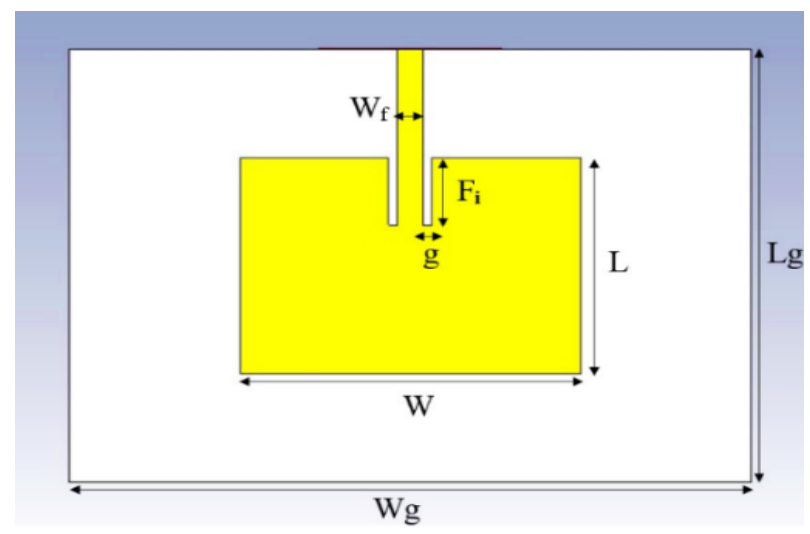

Fig. 2: A) the Geometrical View of RPA.

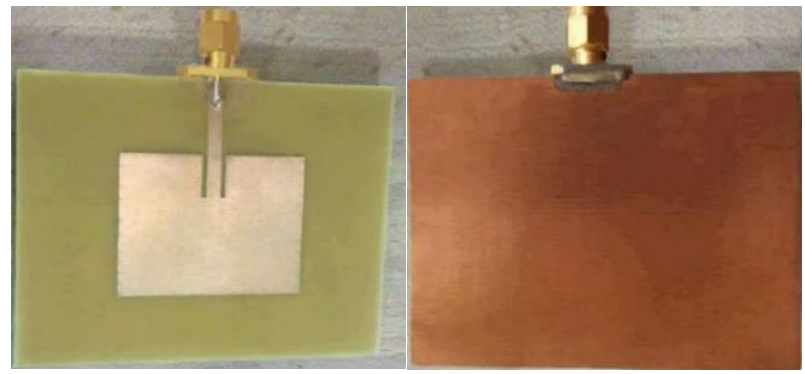

Fig. 2: B) Top and Bottom Photographic View of RPA after Fabrication.

\subsection{Design of dual rectangular patch array antenna}

The modern planar antenna consists of two shape uniform patch array antennas with the practical feeding of the quarter wavelength that is fabricated by using commercial electromagnetic software (CST). The geometric patch array antenna is made of PEC (Perfect Electric Conductor) material that can be made of different metals such as silver, copper, and etc. [7]. However, in this paper copper has been used with its thickness (Mt) of $0.035 \mathrm{~mm}$ to design the PEC of the antenna single rectangular patch and modern array antenna. The length (L) and width (W) of each patch array antennas are $29.05 \mathrm{~mm}$ and $40.7 \mathrm{~mm}$ respectively with a gap (g) of $1 \mathrm{~mm}$ and the inset-fed length ( $\mathrm{Fi}$ ) of $9.07 \mathrm{~mm}$. The distance (d) between two new array elements are $90 \mathrm{~mm}$ which are designed to operate at the resonance frequency of $2.4 \mathrm{GHz}$ for Wi-Fi and WiMAX applications. The size of the ground plane and substrate of the proposed patch array antenna are $\mathrm{Lg}=88.275 \mathrm{~mm}$ and $\mathrm{Wg}=171.4 \mathrm{~mm}$. In order to match two transmission lines of the system, A quarter wave transformer has been used with different impedances. Therefore, the equation (6) was used to provide transformer characteristic impedance $\left(\mathrm{Z}_{0}\right)$ of $70.71 \mathrm{ohms}$, where the load impedance $\left(\mathrm{Z}_{\mathrm{L}}=\right.$ $100 \mathrm{ohms}$ ) and the characteristic impedance of the input transmission line $\left(Z_{\text {in }}=50 \mathrm{ohms}\right)$. In this work, the length of the transformer of $7 \mathrm{~mm}$ was considered to design the structure and the calculation tool of the CST Microwave software was used to calculate the width of the transformer and the transmission line. The feed line width of the proposed antenna is $\mathrm{Wf}=3.137 \mathrm{~mm}$, W0 $=1.641 \mathrm{~mm}$ and WL. $=0.7236 \mathrm{~mm}$ where the characteristic impedances are $(50$, 
70.7 and 100) ohms respectively. Figure ( $3 a \& 3 b)$ indicate the geometric shape and fabrication of dual patch array antenna (DPAA) for wireless communication as shown below.

$$
\mathrm{Z}_{0}=\sqrt{\mathrm{Z}_{\mathrm{L}} \mathrm{Z}_{\text {in }}}
$$

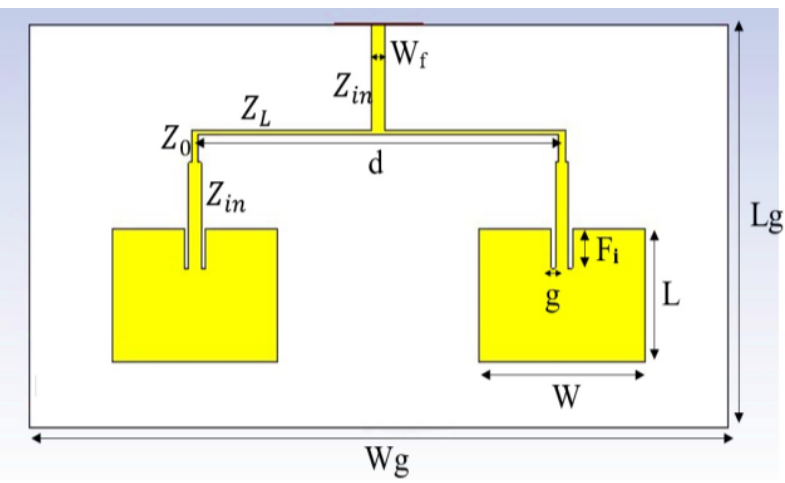

Fig. 3: A) the Geometrical View of DPAA with Inset-Feed.
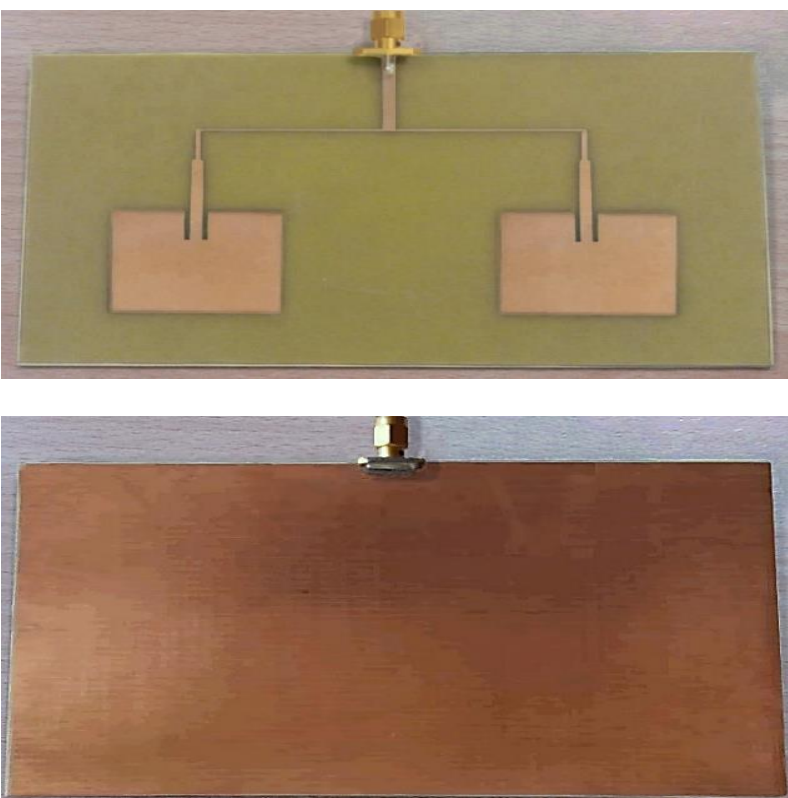

Fig. 3: B) Top and Bottom Photographic View of DPAA after Fabrication.

\section{Result and discussion}

\subsection{Results of single rectangular patch antenna}

In order to simulate and evaluate the result of characteristic parameters of the proposed single microstrip patch antenna, the computer simulation technology software (CST) was used. This software is applied widely for designing of different modern antennas because of having the ability to examine the performance of varies antenna designs such as directivity, gain, S-parameters, voltage standing wave ratio (VSWR) and antenna efficiencies. The first parameter of the rectangular patch antenna that was obtained from the simulated structure is the gain $(\mathrm{G})$ of the first and second band frequency as depicted in figure 4 . The below graph indicates the maximum gain of the traditional microstrip antenna that is about $5.3 \mathrm{~dB}$ and 4.97 $\mathrm{dB}$ at the frequency operation $2.42 \mathrm{GHz}$ and $3.53 \mathrm{GHz}$ respectively. To more analyze the dual-band antenna design, the return loss (S11) results of the antenna were simulated. This parameter is responsible for informing the user how much power is reflected from the transmitted power to the antenna and selecting a specific range of frequency to operate antennas. Although the value obtained of S11 becomes more negative, the return loss decreases and increases the received power of the antenna [16]. The return loss generated is less than $-30 \mathrm{~dB}$ at the lower-frequency band and about $-11 \mathrm{~dB}$ at the higher-frequency band for this designed antenna as shown in figure [5].

The antenna directivity is a significant parameter of antenna designs because if the directivity or the gain is not optimal, the radiating patch will radiate arbitrarily and deteriorate [16]. The maximum directivity of the system was obtained for both band are 7.15 and 6.82 $\mathrm{dBi}$ with its efficiency of -2.11 and $-2.37 \mathrm{~dB}$ respectively. The radiation pattern is also an important characteristic antenna because it indicates how electromagnetic energy radiated by antennas .in addition, this parameter is responsible for distributing the energy of the antenna radiation over a free space or any specific surface. Hence, a 3- dimensional plot of the antenna radiation pattern has been plotted with its polar plots as illustrated in figure 6 .

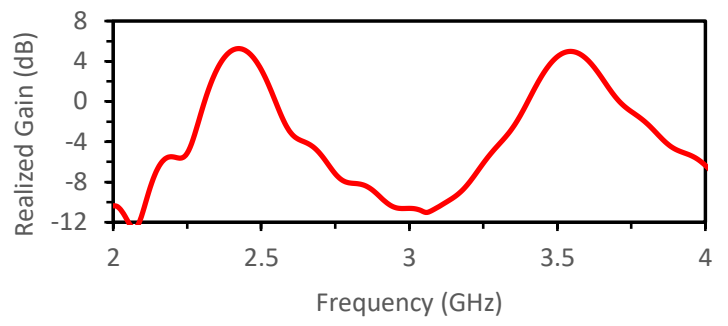

Fig. 4: Simulated Realized Gain versus Frequency of the Original RMSA.

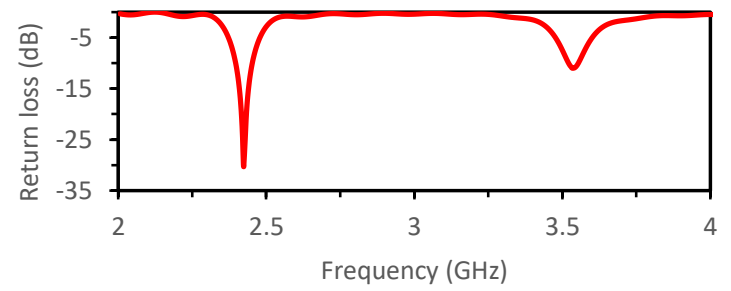

Fig. 5: Simulated Return Loss versus Frequency of the RMSA.
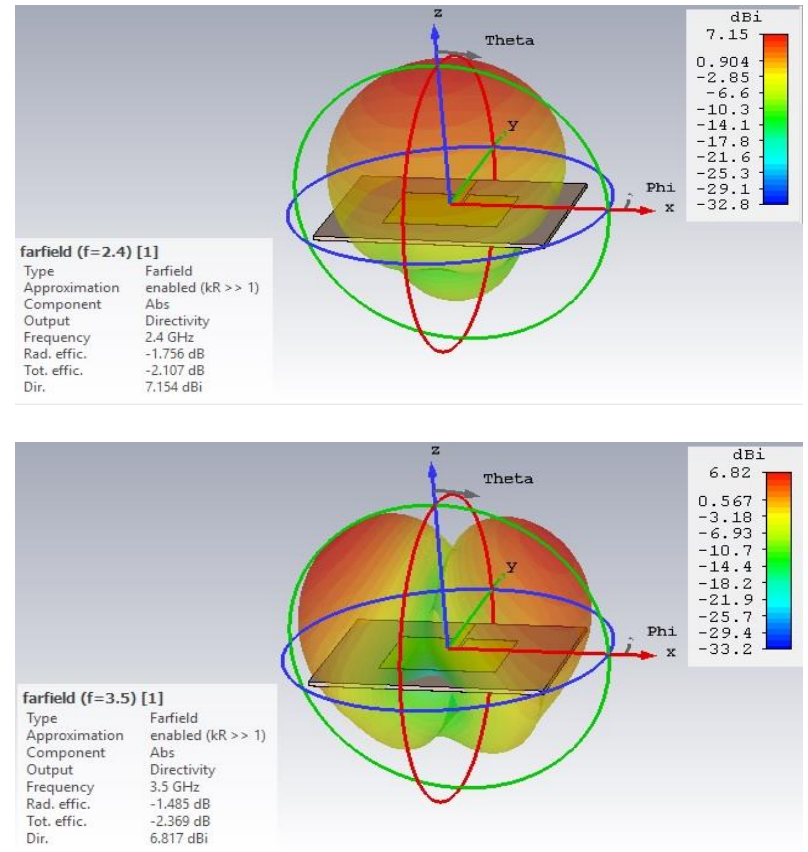

Fig. 6: 3-Dimensional Plot of the Antenna Radiation Pattern at 2.4 Ghz and 3.5 Ghz.

\subsection{Results of dual rectangular patch array antenna}

After fabricating and obtaining a good result from the single rectangular patch antenna design, the researcher proceeded with the design of dual uniform patch array antenna to enhance the directivity and gain of the antenna. The maximum realized gain of the dual 
patch array antenna is about $8.25 \mathrm{~dB}$ and $7.6 \mathrm{~dB}$ at both resonance frequencies of $2.43 \mathrm{GHz}$ and $3.51 \mathrm{GHz}$. Figure 7 illustrates the gain (G) of the antenna which is the main simulated parameter of this antenna that has been obtained from the modern structure. The dual patch antenna gives a very good match value of simulated reflection coefficient $(\mathrm{S} 11<-10 \mathrm{~dB})$ for both frequency bands of $2.43 \mathrm{GHz}$ and $3.5 \mathrm{GHz}$ for an input impedance of $50 \mathrm{ohms}$. At first frequency operation, the antenna records a return loss of $-28.25 \mathrm{~dB}$ with a return loss of $-22.12 \mathrm{~dB}$ for the second band as shown in figure 8 . The Simulated broadside directivity versus frequency of dual elements is depicted in figure 9 and its achieved maximum value is $10.4 \mathrm{dBi}$ and $8.76 \mathrm{dBi}$ at operating frequency of $2.4 \mathrm{GHz}$ and $3.5 \mathrm{GHz}$ respectively.

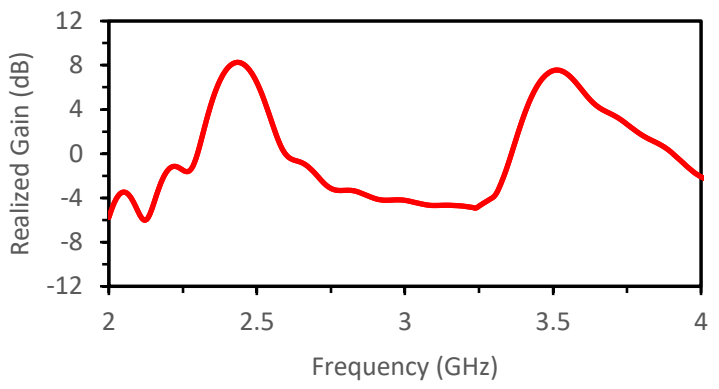

Fig. 7: Simulated Realized Gain versus Frequency of the Dual Patch Antenna.

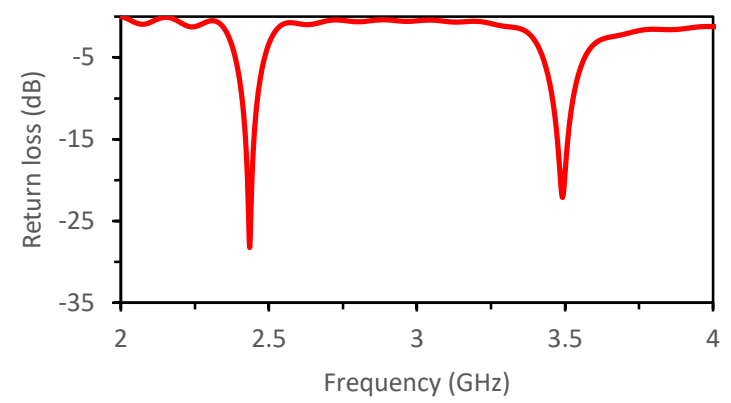

Fig. 8: Simulated Return Loss versus Frequency of the Dual Patch Antenna
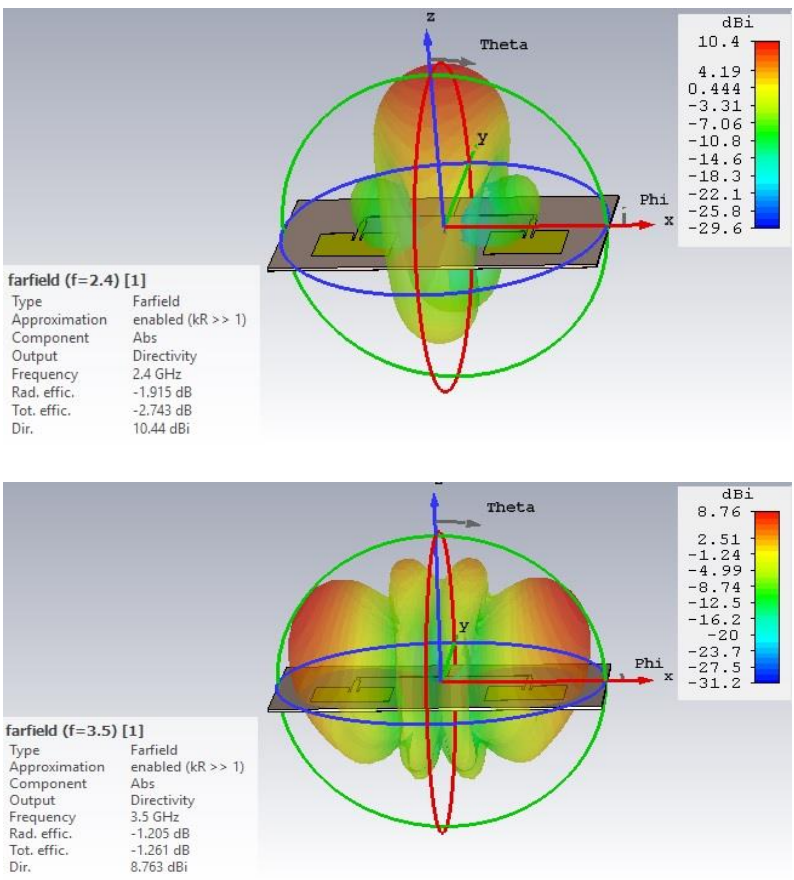

Fig. 9: 3- Radiation Pattern of Dual Patch Elements at 2.4 Ghz and 3.5 Ghz.
To evaluate and better understand the dual-band antenna design, the antennas were fabricated on FR4 using Advantest network analyzer (Vector Network Analyzer device). After design the modern antenna (dual patch antenna), the magnitude obtained parameters of the modern increase as compared with the parameters of the simple rectangular patch antenna. The maximum simulated gain of the new structure antenna was enhanced from 5.25 to $8.25 \mathrm{~dB}$ at first band frequency and from 4.97 to $7.56 \mathrm{~dB}$ at second band frequency. The magnitude of this parameter has been improved about 1.57 times of its actual value for minimum resonance frequency and more than 1.52 times of the magnitude of the single patch antenna at maximum resonance frequency. The measurement pick gain of the single patch was increased as compared with simulated value for both band. The results of simulated and measurement gain were very close at high frequency band as demonstrated in figure 10 .

The measurements of return loss (S11) were performed and the single patch antenna gives a very good measurement result of the reflection coefficient of $-36.26 \mathrm{~dB}$ for the high-frequency band as compared with the simulated result. At low band of $2.392 \mathrm{GHz}$, the measurement return loss of the antenna is about -23.69 as shown in figure 11 . Test results of the dual patch antenna were performed and very close to computer simulation results for both of those bands. The measurement results of the antenna return loss are about -20.86 $\mathrm{dB}$ and $-21.38 \mathrm{~dB}$ at low frequency and high-frequency bands respectively as plotted in figure 11 . Measurements of the return loss for the dual patch antenna's lower- frequency band were better than $-10 \mathrm{~dB}$ from 2.403 to $2.469 \mathrm{GHz}$. This frequency band is suitable for channels 1 to 13 for Wi-Fi devices and the antenna can be utilized in the IEEE $802.11 \mathrm{~b}$ for channels 1,6 , and 11 ; in the IEEE $802.11 \mathrm{n}$ protocol for channels 3 and 11 ; and in the IEEE $802.11 \mathrm{~g} / \mathrm{n}$ for channels 1, 5, 9, and 13 for Wi-Fi applications. The result of S11 for the higher-frequency bandwidth of the modern antenna was better than $-10 \mathrm{~dB}$ from 3.47 to $3.57 \mathrm{GHz}$, eligible for WiMAX applications.

The measurements of free space H- and E-plane pattern were also performed on the prototype antenna, with a directivity of $\boldsymbol{\theta}$ presented in figures 12 . The radiation pattern directivity $(\boldsymbol{\theta})$ is maximum at $0 \mathrm{deg}$. when $\phi=90 \mathrm{deg}$. for $2.4 \mathrm{GHz}$. The directivity $\boldsymbol{\theta}$ is inclining toward $0 \mathrm{deg}$. because of the ground plane. The radiation pattern is almost symmetrical at $\phi=0 \mathrm{deg}$. and $\phi=90 \mathrm{deg}$. for the single patch. The effects of dual uniform patch array design increase the directivity and gain toward $0 \mathrm{deg}$. in the lower-frequency band. The pattern for $3.5 \mathrm{GHz}$ approaches to a maximum value at 60 and 300 degrees with two nulls at 0 and 180 degrees. The directivity $\boldsymbol{\theta}$ when $\phi=90$ degrees is less than when $\phi=0$ deg., and this difference is greater as compared with the lower-frequency band. At the higher resonant frequency, the radiation pattern is nearer to being more broadsided and omnidirectional when $\phi=0$ deg.

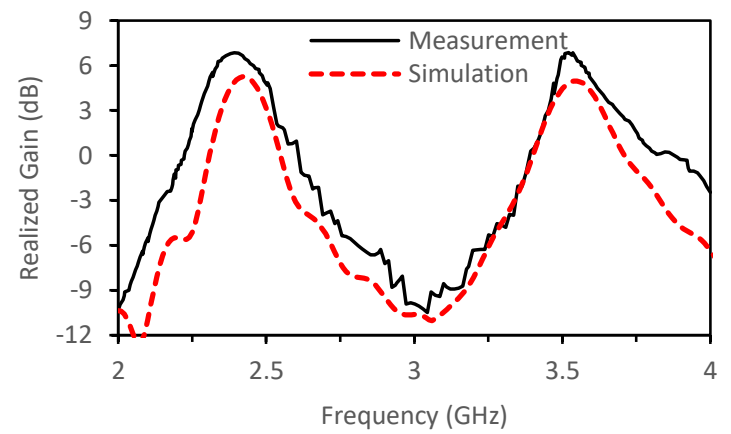

Single Patch

\subsection{Comparison of single and dual patch antennas}




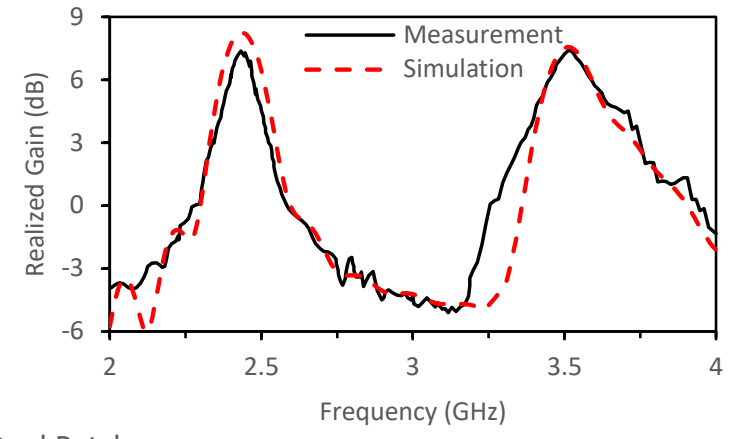

Dual Patch

Fig. 10: The Measured and Simulated Realized Gain of Single and Dual Patch.
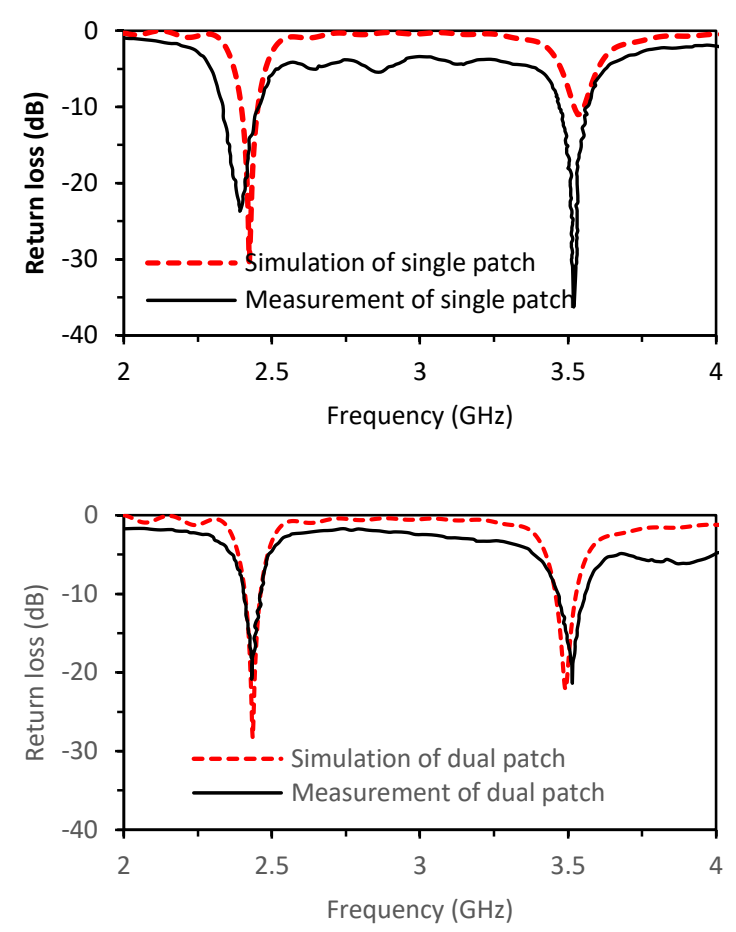

Fig. 11: The Measured and Simulated Return Loss for the Single and Dual Patch Antenna.

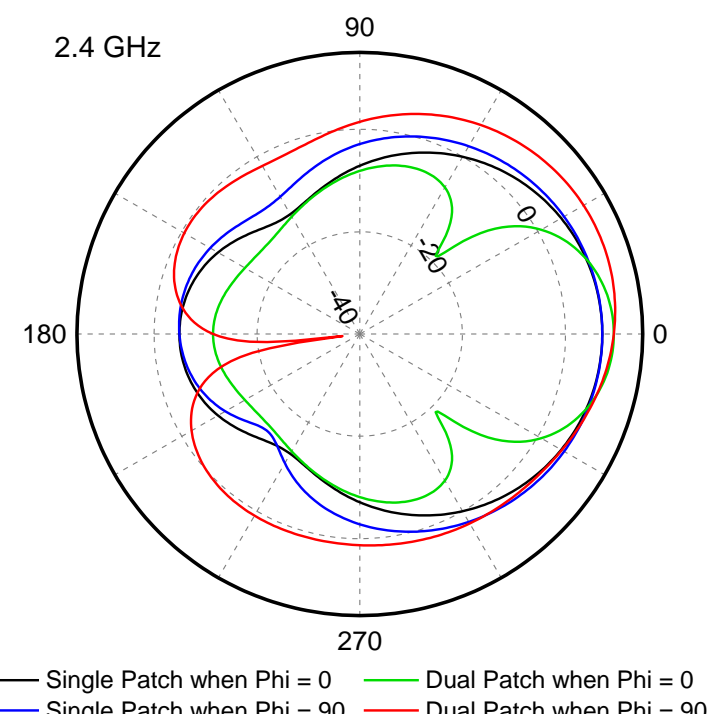

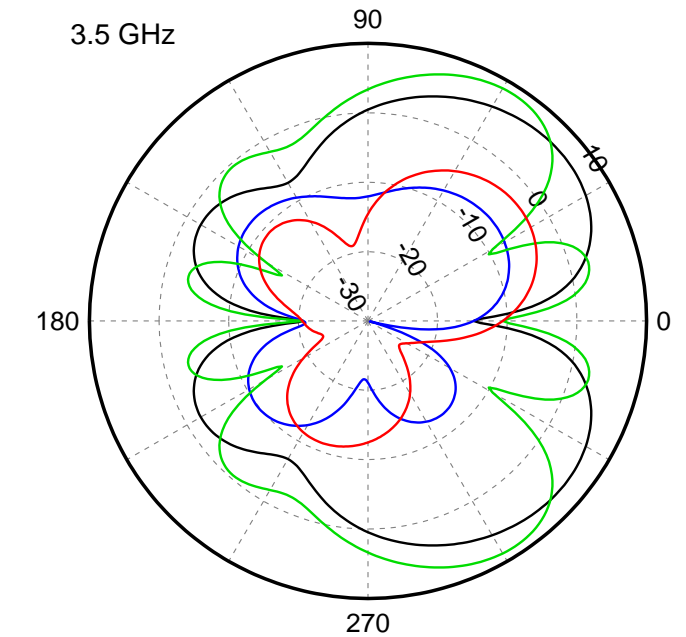

$\begin{array}{ll}\text { Single Patch when Phi }=0 & \text { Dual Patch when } \mathrm{Phi}=0 \\ \text { Single Patch when Phi }=90 & \text { Dual Patch when } \mathrm{Phi}=90\end{array}$

Fig. 12: Curves Show the Directivity $\theta$ for the Single and Dual Patch Antenna.

Table 1: Comparison of Measurement and Simulated Characteristics of The Antennas

\begin{tabular}{lllll}
\hline Parameters & \multicolumn{3}{c}{$\begin{array}{c}\text { Single Patch An- } \\
\text { tenna }\end{array}$} & $\begin{array}{c}\text { Dual Patch An- } \\
\text { tenna }\end{array}$ \\
\hline & $2.4 \mathrm{GHz}$ & $3.5 \mathrm{GHz}$ & $2.4 \mathrm{GHz}$ & $3.5 \mathrm{GHz}$ \\
Simulated Directivity (dBi) & 7.15 & 6.82 & 10.4 & 8.76 \\
Measurement Directivity (dBi) & 8.705 & 8.729 & 9.501 & 8.967 \\
Simulated Maximum Gain (dB) & 5.25 & 4.97 & 8.25 & 7.56 \\
Measurement Maximum Gain & 6.853 & 6.864 & 7.377 & 7.422 \\
(dB) & & & -28.25 & -22.12 \\
Simulated Return loss (dB) & -30.32 & -10.99 & -20.86 & -21.38 \\
Measurement Return loss (dB) & -23.68 & -36.26 & -20.56 \\
Simulated Bandwidth (MHz) & 56.23 & 32.95 & 52.40 & 74.56 \\
Measurement Bandwidth (MHz) & 125.20 & 97.58 & 65.82 & 98.96 \\
Simulation of (VSWR) & 1.06 & 1.78 & 1.08 & 1.16 \\
Measurement of (VSWR) & 1.139 & 1.031 & 1.19 & 1.186 \\
Simulated Frequency & 2.42 & 3.53 & 2.43 & 3.49 \\
Operation (GHz) & & & & \\
Measurement Frequency & 2.392 & 3.521 & 2.433 & 3.515 \\
Operation (GHz) & & & & \\
\hline
\end{tabular}

Table 1 shows a summary comparison of the measurement and simulated radiation pattern characteristics of single and dual patch antennas across the minimum and maximum band frequency of 2.4 $\mathrm{GHz}$ and $3.5 \mathrm{GHz}$. It can be seen in the above table that the maximum simulated gain achieved by the array antenna is much more than the gain of the single antenna that it has been increased by about percentage 60 of the single patch gain at first band and more than percentage 50 at second frequency band. The measurement gain of the dual design was also improved for both bands. The measurement and simulated simple rectangular patch antenna only gives a maximum directivity of about $(8.71 \mathrm{dBi}$ and $8.729 \mathrm{dBi})$ and $(7.15 \mathrm{dBi}$ and $6.82 \mathrm{dBi}$ ) at first and second frequency bands, whereas the measurement and simulation of the designed dual patch array antenna provides an impressive directivity of $(9.5 \mathrm{dBi}$ and $8.97 \mathrm{dBi})$ and $(10.4 \mathrm{dBi}$ and $8.76 \mathrm{dBi})$ respectively. Besides, the simulated dual structure has a decreased return loss of -22.12 as compared to the return loss of simply designed antennas at high band. The measurements of the return loss are almost the same for the dual antenna that this parameter leads to decrease the rate of reflected power in the antenna. The measurement bandwidth generated a good value of bandwidth for both antennas and frequency bands as compared with simulated bandwidths. The design of array structure also gives a good magnitude of the voltage standing wave ratio (VSWR) of the antenna, in particular measurement values. The measurement VSWR is less than 1.2 for high and low bands of both fabricated structures. Nevertheless, it is written in the table, that the measurement and simulated frequency operations of the last antenna configuration (dual) is much closer than the resonance frequency of the antenna at high band. They have approximately same 
value for the modern antenna at the low-frequency band. Overall, all parameters of the array antenna have been improved as compared to the characteristics of the traditional rectangular patch antenna.

\section{Conclusion}

In this study, the planar dual patch array antenna was fabricated to enhance the antenna's gain and directivity for the Wi-Fi/WiMAX applications. The planar structure gives good simulated and measurement results with a perfect reflection $(\mathrm{S} 11<-10 \mathrm{~dB})$ for an input impedance of $50 \mathrm{ohms}$

In short, it was possible to design and produce a dual-band antenna for Wi-Fi/WiMAX using a dual microstrip patch array antenna with inset feeding. The antenna provides high band coverage of 3.58 to $3.65 \mathrm{GHz}$ and low-frequency coverage of 2.412 to $2.478 \mathrm{GHz}$, with good radiation patterns for both of those bands. Overall, the planar structure of the array antenna helps the fabrication of $\mathrm{Wi}-\mathrm{Fi} / \mathrm{Wi}$ MAX applications in wireless communication.

\section{Acknowledgements}

The authors would like to thank the University of Birmingham in UK for fabricating the antennas and Erbil Polytechnic University for supporting this work.

\section{References}

[1] Constantine A. B., “Antenna theory: analysis and design. Microstrip Antennas, "' Third edition, John wiley \& sons, New York, (2005).

[2] Choukiker Y.K., Behera S.K., Pandey B.K. and Jyoti, R., “'Optimization of plannar antenna for ISM band using PSO,' In Computing Communication and Networking Technologies (ICCCNT), Second International Conference, Karur, (2010), pp. 1-4. IEEE. https://doi.org/10.1109/ICCCNT.2010.5591601.

[3] kumar Deb P., Moyra T. and Bhowmik P., "Return loss and bandwidth enhancement of microstrip antenna using Defected Ground Structure (DGS)," In Signal Processing and Integrated Networks (SPIN), 2nd International Conference, Noida, (2015), pp. 25-29. IEEE.

[4] Saunders S. and Aragón-Zavala A., "Antennas and propagation for wireless communication systems,', John Wiley \& Sons, New Jersey, (2007).

[5] Soni A., Sinha P. and Gupta H.K., "'Design of E Shaped Slotted Rectangular Microstrip Patch Antenna for Wireless LAN," International Journal of Electrical, Electronics and Computer Engineering, 3(1), (2014), 79-82.

[6] Gupta H.K. and Singhal P.K., "Patch Antennas Designs with Defect Ground Structure in Efficient Rectenna Design for Wireless Power Transmission,"' IJECCT, 2(4), (2012), 37-40.

[7] Sharma P., Arora D. and Gupta H., "Designing Superdirective Patch Antenna Array Using Metamaterial,', International Journal of Engineering, 1(8), (2012), 1-4.

[8] Kaushal D., Shanmuganantham T. and Sajith K., "Dual band characteristics in a microstrip rectangular patch antenna using novel slotting technique,' In Intelligent Computing, Instrumentation and Control Technologies (ICICICT), International Conference, (2017, July), pp. 957-960. IEEE.

[9] Hu Y., Jackson D.R., Williams J.T., Long S.A. and Komanduri V.R. "Characterization of the Input Impedance of the Inset-Fed Rectangular Microstrip Antenna," IEEE Transactions on Antennas and $\begin{array}{lll}\text { Propagation, } & \text { 56(10), } & \text { (2008), }\end{array}$ https://doi.org/10.1109/TAP.2008.929532.

[10] Rajeswari R., Sudarshini P. and Vidya harini S.V., "Design of Dua Band Dissimilar Patch Size Array Antenna for Wireless Applications," International Journal of Information Sciences and Tech$\begin{array}{llll}\text { niques } & \text { (IJIST), } & 4(3), & \text { (2014), }\end{array}$ https://doi.org/10.5121/ijist.2014.4305.

[11] Sauter M., "Beyond $3 G$ - Bringing Networks, Terminals and the Web Together,' John Wiley \& Sons Ltd, UK: Sussex, (2009).

[12] Madhav B.T.P., Rao J.C., Nalini K. and Indira N.D., "Analysis of Coaxial Feeding and Strip Line Feeding on the Performance of the Square Patch Antenna,' Int. J. Comp. Tech. Appl., 2(5), (2011), 1352-1356.
[13] Martin L.J., Ooi S., Staiculescu D., Hill M.D., Wong C.P. and Tentzeris M.M., "Effect of permittivity and permeability of a flexible magnetic composite material on the performance and miniaturization capability of planar antennas for RFID and wearable wireless applications,' Ieee Transactions on Components and Packaging Technologies, 32(4), (2009), 849-858 https://doi.org/10.1109/TCAPT.2009.2032767.

[14] Gupta K.C., Garg R., Bahl I. and Bhartia P., "Microstrip lines and Slot lines,' Second Edition, Artech House INC, London: Boston, ISBN 0-89006-766-X, (1996).

[15] Singh J., “Inset Feed Microstrip Patch Antenna," International Journal of Computer Science and Mobile Computing (IJCSMC), 5(2), (2016), $324-329$.

[16] Balanis C.A., “Antenna theory: analysis and design,'” Wiley-Interscience, USA: New York, (2012)

[17] Naik K.K., "Asymmetric CPW-fed SRR Patch Antenna for WLAN/WiMAX Applications,", AEU-International Journal of Electronics and Communications, 93, (2018), 103-108. https://doi.org/10.1016/j.aeue.2018.06.008. 